\title{
NECOP Propagation Experiment: Rain-Rate Distributions Observations and Prediction Model Comparisons
}

\author{
J. S. Ojo and S. E. Falodun \\ Department of Physics, Federal University of Technology Akure, P.M.B. 704, Akure, Nigeria \\ Correspondence should be addressed to J. S. Ojo, josnno@yahoo.com
}

Received 15 February 2012; Accepted 20 May 2012

Academic Editor: Thomas Kürner

Copyright ( $) 2012$ J. S. Ojo and S. E. Falodun. This is an open access article distributed under the Creative Commons Attribution License, which permits unrestricted use, distribution, and reproduction in any medium, provided the original work is properly cited.

\begin{abstract}
Empirical distribution functions for one-minute average rain-rate values were compiled for three station year of observations at Nigeria environmental and climatic observatory (NECOP) propagation experiment terminal sites. The empirical distribution functions were compared with cumulative distribution functions generated using four different rain-rate distribution models. It is found that although each of the models shows similar qualitative features at lower exceedance of time, the characteristic at higher time percentages shows quantitative difference from the experimental data except the improved version of Moupfouma model. The results further show that the rainfall rate and the microwave propagation characteristics in this region are out of accord with International Telecommunication Union predictions. This information is vital for predicting rain fading cumulative probability distributions over this region.
\end{abstract}

\section{Introduction}

The Nigeria environmental and climatic observatory (NECOP) experiment was designed for the following purposes among others: to generate data bank on the measured parameters for observatory and research purposes, to serve as a tool for planning acceptable terrestrial and satellite communication networks, as well as for the prediction of weather, hydrological purposes, and for agricultural usage. Among the parameters that were measured by the equipment in each site are the total rain accumulation and rain rate. This paper is based on the analysis of these two parameters, and comparisons were made with some existing rain-rate prediction models. The primary atmospheric phenomenon that contributed to degradation of satellite signals above $10 \mathrm{GHz}$ is attenuation due to rain. The severity of rain impairments increases with frequency and varies with regional locations [1]. Hence, in order to successfully estimate rain attenuation along the link path, the point rainfall rate characteristic must be available in the location of interest. For such rainfall rate characteristics, information such as rainfall rate integration time, average rainfall cumulative distribution, and worst-month rainfall rate distributions are all required by a radio link planner in order to estimate path loss [2].

In this paper, continuous measurement of point rainfall rate data of 1-minute integration were used to find the best rainfall cumulative distribution model for three distributed sites: The Federal University of Technology, Akure, Ondo State (FUTA), University of Lagos, Lagos State (UNILAG), and University of Yola, Adamawa State (UNIYOLA).

Four different rain rate distribution models were considered in this study; the ITU rain-rate model as recommended by [3], the rain rate prediction model developed by RiceHolmberg, RH [4], the modified version of the model developed by Moupfouma and Martin's [5, 6] and the Kitami's model [7]. The RH uses local climatological data to generate the two parameters needed to make prediction: the average annual precipitation, $M$, and the thunderstorm ratio $\beta$. The RH parameters may be calculated from the local long-term average annual precipitation accumulation, the number of thunderstorm days, and the maximum monthly precipitation in 30 years. The parameter may also be extrapolated from the maps presented by Rice and Holmberg [4]. Moupfouma and Martins also derived a very simple empirical model which provides a good description 
TABLE 1: Site characteristics of the study locations.

\begin{tabular}{|c|c|c|c|c|c|c|}
\hline Station & $\begin{array}{l}\text { Latitude } \\
\left({ }^{\circ} \mathrm{N}\right)\end{array}$ & $\begin{array}{l}\text { Longitude } \\
\left({ }^{\circ} \mathrm{E}\right)\end{array}$ & Height above sea level & $\begin{array}{c}\text { Average annual rainfall } \\
\text { (mm/year) }\end{array}$ & Observation period & Region climate \\
\hline FUTA & 7.17 & 5.18 & 358 & 1485.6 & $\begin{array}{l}16 \text { months (Jun. } \\
\text { 2010-Sept. 2011) }\end{array}$ & Rain forest zone \\
\hline UNILAG & 6.27 & 3.24 & 40 & 1626.2 & $\begin{array}{l}12 \text { months (Oct. } \\
\text { 2007-Nov. 2008) }\end{array}$ & Coastal region \\
\hline UNIYOLA & 9.14 & 12.28 & 174 & 948.5 & $\begin{array}{l}14 \text { months (Nov. } \\
\text { 2009-Dec. 2010) }\end{array}$ & Semiarid \\
\hline
\end{tabular}

of the global distribution for cumulative rainfall rates above $2 \mathrm{~mm} / \mathrm{h}$. The model combines both log-normal and gamma distributions. The model also allows the prediction of the cumulative distribution of rainfall rate in temperate and tropical regions by using one-minute integration time of point rainfall in any location of interest. Details of the model are fully reported in [4].

Kitami's model was proposed by Ito and Hosoya, as reported in [7] to obtain 1-minute rain rate distribution using thunderstorm ratio and average annual precipitation as regional climatic parameter. The data used are the Kitami Institute of Technology data bank, which contains 290 datasets for 30 countries including the tropical region. The ITU P-837-6 model was based on the improved version of Salonen Baptisa [8] model. The method involves the use of a database of the following meteorological parameters: annual rainfall amount of convective-type rain $M_{c}(\mathrm{~mm})$, annual rainfall amount of stratiform-type rain $M_{s}(\mathrm{~mm})$, and probability of rainy $6 \mathrm{~h}$ periods $P_{r 6}(\%)$. The parameters $\left(P_{r 6}\right.$, $M_{c}$, and $M_{s}$ ) are available from ITU's 3 M Group Web site, each of which is matched to a (latitude, longitude) pair [3].

\section{Experimental Sites and Measurement}

The rainfall rate data were collected at the Federal University of Technology, Akure campus in Ondo State (FUTA), University of Lagos campus, Lagos State (UNILAG), and University of Yola campus in Adamawa State (UNIYOLA). Detail characteristics of each of the measurement site are listed in Table 1.

Rainfall intensities measurements are made by a tipping bucket raingauge which stands $146 \mathrm{~mm}$ high as part of NECOP setup in all the sites. The rain gauge has sensitivity of about $0.1 \mathrm{~mm}$ and a data acquisition unit along with other sensors in unit that measured the following parameters: soil moisture content (volume of water), wind speed and wind direction, air temperature, and relative humidity among others. For the rain gauge measurement, the rain water is collected in a standard funnel and is converted into drops of equal sizes. The number of drops collected every 10 seconds is counted electronically and finally averaged over 1 minute. The AGC voltage of each channel is continuously sampled and stored in digital form, together with the date and time of each rain gauge tip. The calibration of the rain gauge is maintained by cleaning the capillary. The overall reliability of the gauge is extremely high due to the simple drop-forming mechanism. The reliability has to be ensured by keeping it

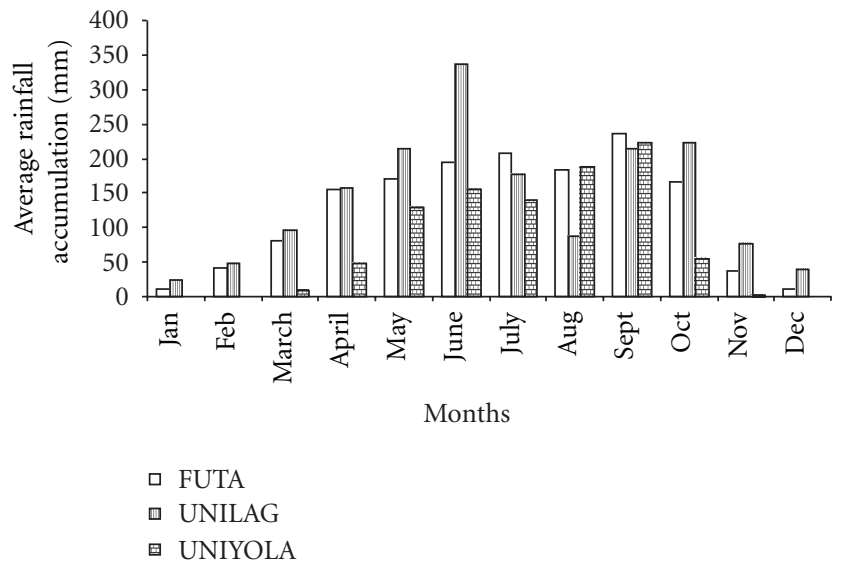

Figure 1: Average monthly rainfall accumulations during the observation period.

clean, so that dust particles do not obstruct the free flow water [9].

\section{Results and Discussions}

3.1. Distribution of Rain Rate. Figure 1 shows the average monthly rainfall accumulations during the observation period. The average monthly rainfall depends on the effects of movement of the Intertropical Convergence Zone (ITCZ). In summer, the ITCZ discontinuity follows the sun northward, as a result, more and more of the country comes under the influence of the moisture-laden tropical maritime air. As summer wanes, the zone shifts southward, bringing an end to the rainy season. Nigeria has two seasons, dry (Nov., Dec., Jan., and. Feb) season, and wet (the rest of the calendar year) season. Rainfall usually falls during the wet season and during this period the ITCZ moves across the country.

It could be observed that both the rain forest region (FUTA) and the semiarid region (UNIYOLA) recorded their peak average monthly rainfall accumulation in the month of September with 234 and $224 \mathrm{~mm}$, respectively, while the coastal region has the wet month in June with average rainfall accumulation of about $336 \mathrm{~mm}$. Due to ITCZ movement, rain continues to fall even during dry season in the rain forest and coastal regions.

3.2. Comparison of Measured and Model Data. The results of predictions by the four different rain rate-models when 
TABLE 2: The composite comparison statistics for the different models.

\begin{tabular}{|c|c|c|c|c|c|}
\hline \multicolumn{2}{|c|}{ Percentage of time } & \multicolumn{2}{|c|}{$0.1 \%$} & \multicolumn{2}{|c|}{$0.01 \%$} \\
\hline Location & Model & Average relative error & Standard deviation & Average relative error & Standard deviation \\
\hline \multirow{4}{*}{ FUTA } & $\mathrm{RH}$ & 125.0 & 15.0 & 4.6 & 27.2 \\
\hline & ITU & 15.6 & 2.4 & -22.0 & 12.9 \\
\hline & KITAMI & 68.6 & 8.7 & 16.2 & 9.4 \\
\hline & Moupfouma & 11.6 & 2.0 & 4.4 & 2.7 \\
\hline \multirow{4}{*}{ UNILAG } & RH & 9.5 & 2.5 & 23.0 & 16.2 \\
\hline & ITU & 5.2 & 2.0 & 6.0 & 3.8 \\
\hline & KITAMI & 4.5 & 6.1 & -10.0 & 7.6 \\
\hline & Moupfouma & 4.0 & 1.1 & 5.5 & 3.0 \\
\hline \multirow{4}{*}{ UNIYOLA } & RH & 88.0 & 9.9 & 34.1 & 26.0 \\
\hline & ITU & 31.2 & 3.5 & 5.5 & 5.0 \\
\hline & KITAMI & 22.9 & 2.6 & 14.7 & 7.9 \\
\hline & Moupfouma & 30.0 & 3.0 & 4.4 & 4.7 \\
\hline
\end{tabular}

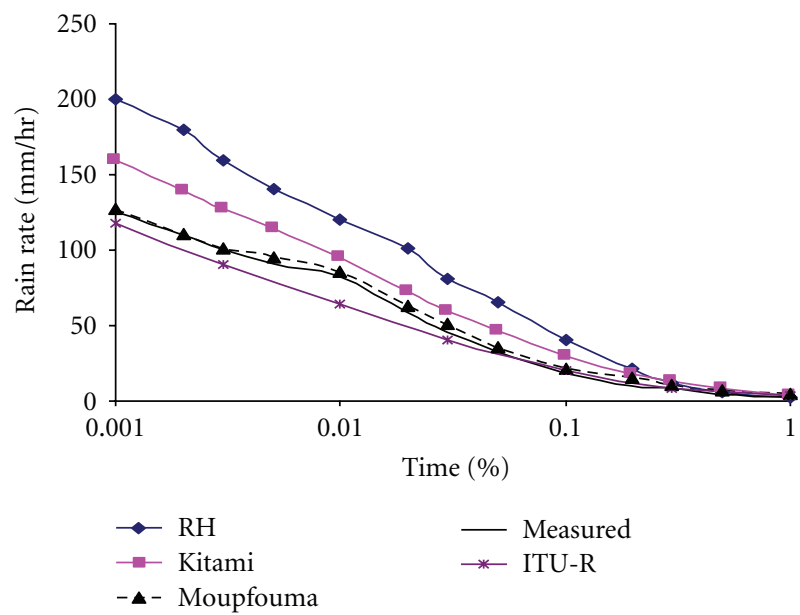

FIGURE 2: Comparison of measured FUTA rainfall data with model predictions.

compared with the measured data from each location were considered to illustrate the differences in the expected rainrate distributions for different locations and rain intensities. It is also needed to know how well a model performs statistically as compared with the measured values. Figures 2, 3, and 4 show the cumulative distribution of measured rainfall rate compared with each of the four predefined models, while Table 2 gives the composite comparison statistics for the different models.

It could be observed that the modified Moupfouma model shows the best prediction accuracy in all the measurement locations among the tested models based on the smaller absolute values of average relative error and standard deviation from the measured data (Table 2 referred). In addition to the statistical analysis, Moupfouma model combines the gamma and log-normal models by approximating a lognormal distribution at the low rain rates and a gamma distribution at high rain rate [10].

The ITU model is judged next suitable model for these locations apart from the statistical analysis because the

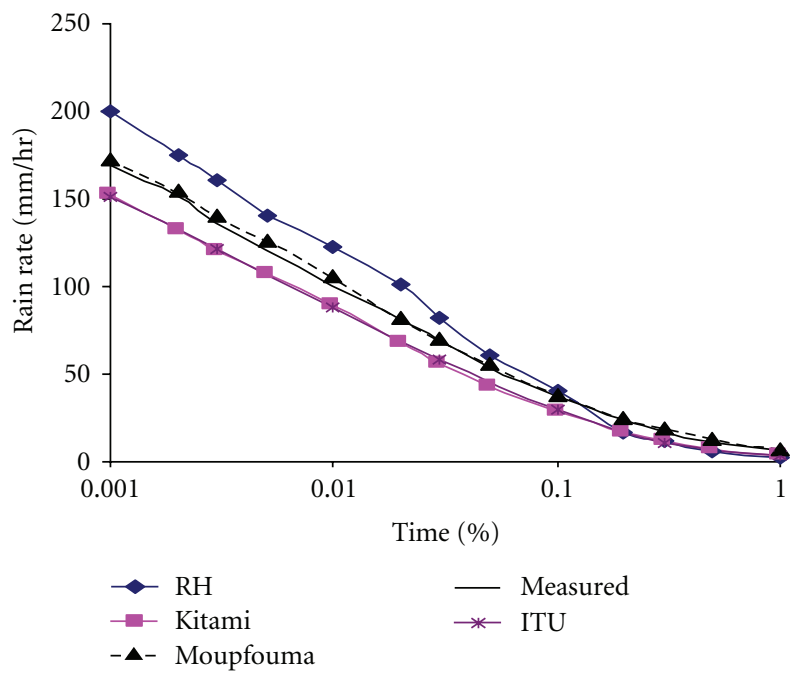

FIgURE 3: Comparison of measured UNILAG rainfall data with model predictions.

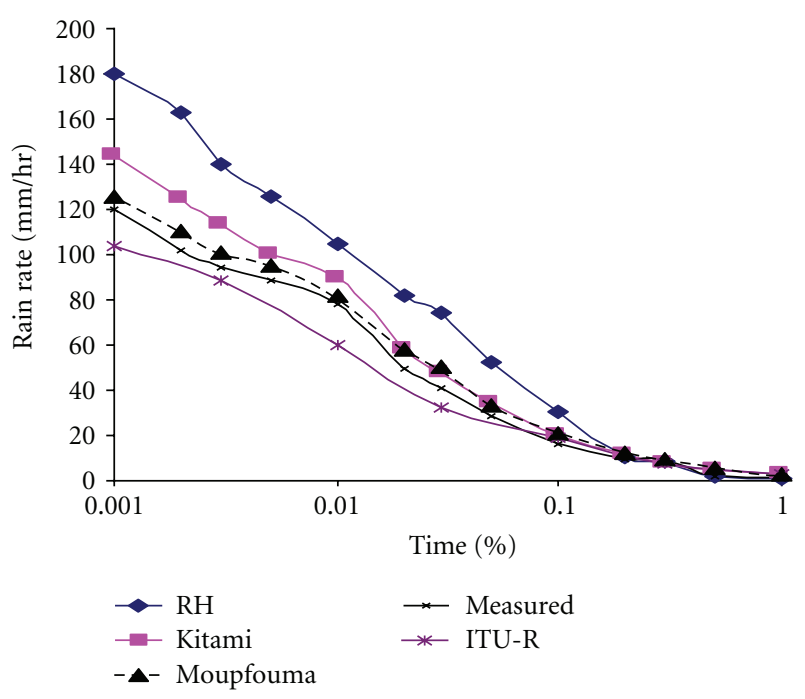

FIgURE 4: Comparison of measured UNIYOLA rainfall data with model predictions. 
rainfall-rate model is based on the conversion to oneminute integration on long-term data of six hours rain accumulation.

The Kitami's model gives a good estimation for low rainfall rates but not fitted for high rainfall rates. The $\mathrm{RH}$ model is not suitable for use in tropical and equatorial climates judging from the statistical analysis, and because the model is based on the rainfall rate measurements in European countries where rainfall rates are moderate.

\section{Conclusion}

In this paper, comparison of rainfall rate was made with measured data and four preexisting models. It was found that Moupfouma model showed a close fit to the measured data for low, medium, and high rainfall rates based on the smaller values of average relative errors and standard deviation. The Moupfouma model is therefore judged suitable for use in predicting rain rates in these locations. The results are vital for system designer to estimate rain degradation along the satellite links over this region. It should be observed that the results are valid for this particular climates, and its applicability for other tropical regions requires further testing.

\section{Acknowledgment}

Authors are indebted to the Centre for Basic Space Science of NASRDA for providing NECOP equipment to each of the sites used for this research.

\section{References}

[1] G. O. Ajayi and E. B. C. Ofoche, "Some tropical rainfall rate characteristics at Ile-Ife for microwave and millimeter wave applications," Journal of Climate \& Applied Meteorology, vol. 23, no. 4, pp. 562-567, 1984.

[2] P. A. Owolabi, T. J. Afullo, and S. B. Mallaga, "Effect of rainfall on millimeter wavelength radio in Gough and Marion Islands," PIERS Online, vol. 5, no. 4, pp. 328-335, 2009.

[3] International Telecommunication Union, "Characteristics of precipitation for propagation modeling," ITU-R Recommendations P.837-6, International Telecommunication Union, Geneva Switzerland, 2012.

[4] P. L. Rice and N. R. Holmberg, "Cumulative time statistics of surface-point rainfall rate," IEEE Transactions on Communications, vol. 21, no. 10, pp. 1131-1136, 1973.

[5] F. Moupfouma and L. Martin, "Modeling of the rainfall rate cumulative distribution for the design of satellite and terrestrial communication systems," International Journal of Satellite Communications, vol. 13, no. 2, pp. 105-115, 1995.

[6] J. S. Ojo, M. O. Ajewole, and L. D. Emiliani, "One-minute rainrate contour maps for microwave-communication-system planning in a tropical country: Nigeria," IEEE Antennas and Propagation Magazine, vol. 51, no. 5, pp. 82-89, 2009.

[7] C. Ito and Y. Hosoya, "Worldwide 1 min rain rate distribution prediction method which uses thunderstorm ratio as regional climatic parameter," Electronics Letters, vol. 35, no. 18, pp. 1585-1587, 1999.
[8] E. T. Salonen and J. P. V. P. Baptista, "New global rainfall rate model," in Proceedings of the 10th International Conference on Antennas and Propagation, Pub N 14-176-436, pp. 2.1822.185, April 1997.

[9] J. S. Ojo, "Rain rate statistics and fade distributions at Ka- and $\mathrm{Ku}$ band frequencies for microwave propagation in the tropical locations," The Nigerian Journal of Space Research, vol. 10, pp. 72-80, 2011.

[10] J. S. Mandeep and S. I. S. Hassan, "Comparison of 1-minute rainfall rate distributions for tropical and equatorial climates," Space Communications, vol. 19, no. 3-4, pp. 193-198, 2004. 

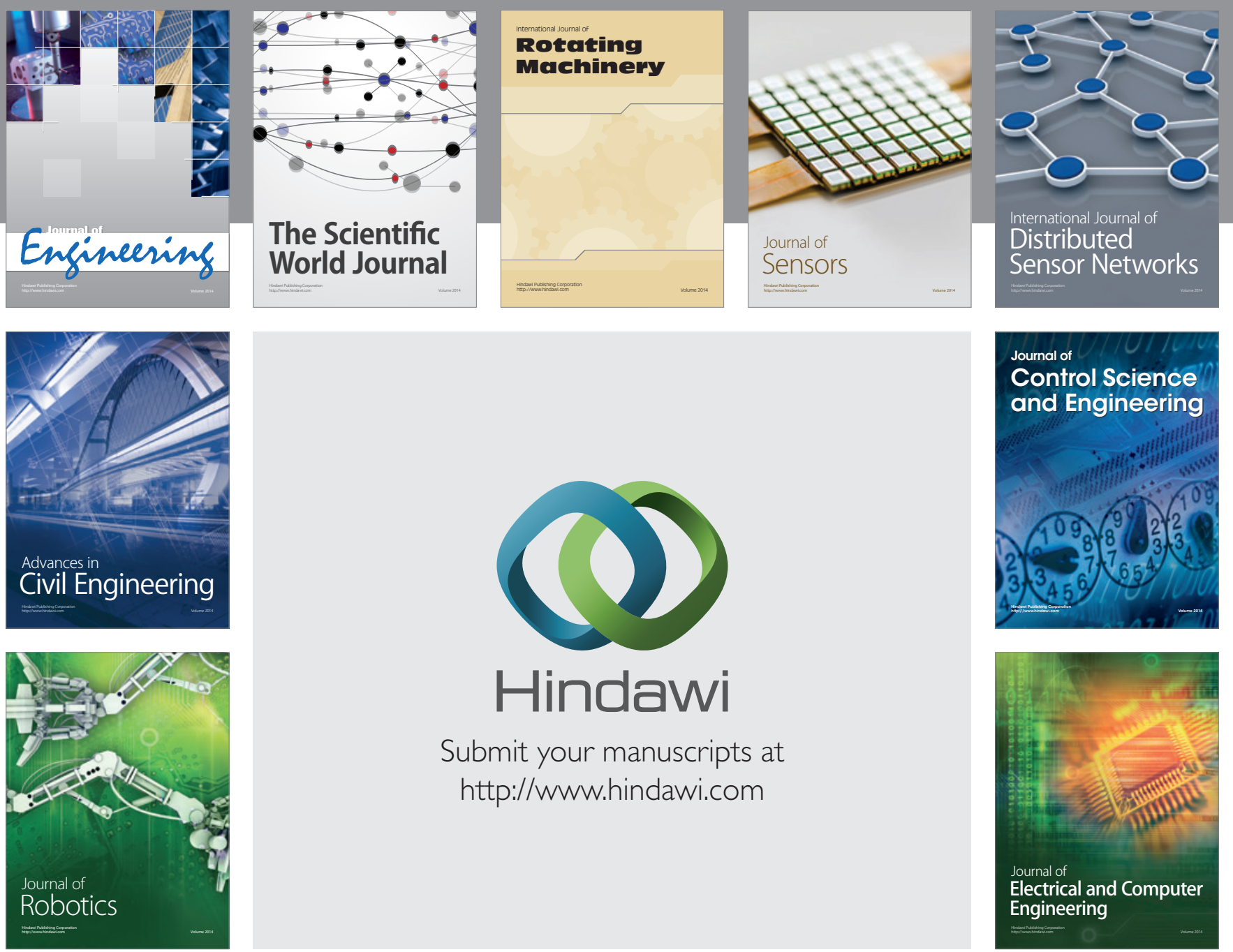

Submit your manuscripts at

http://www.hindawi.com
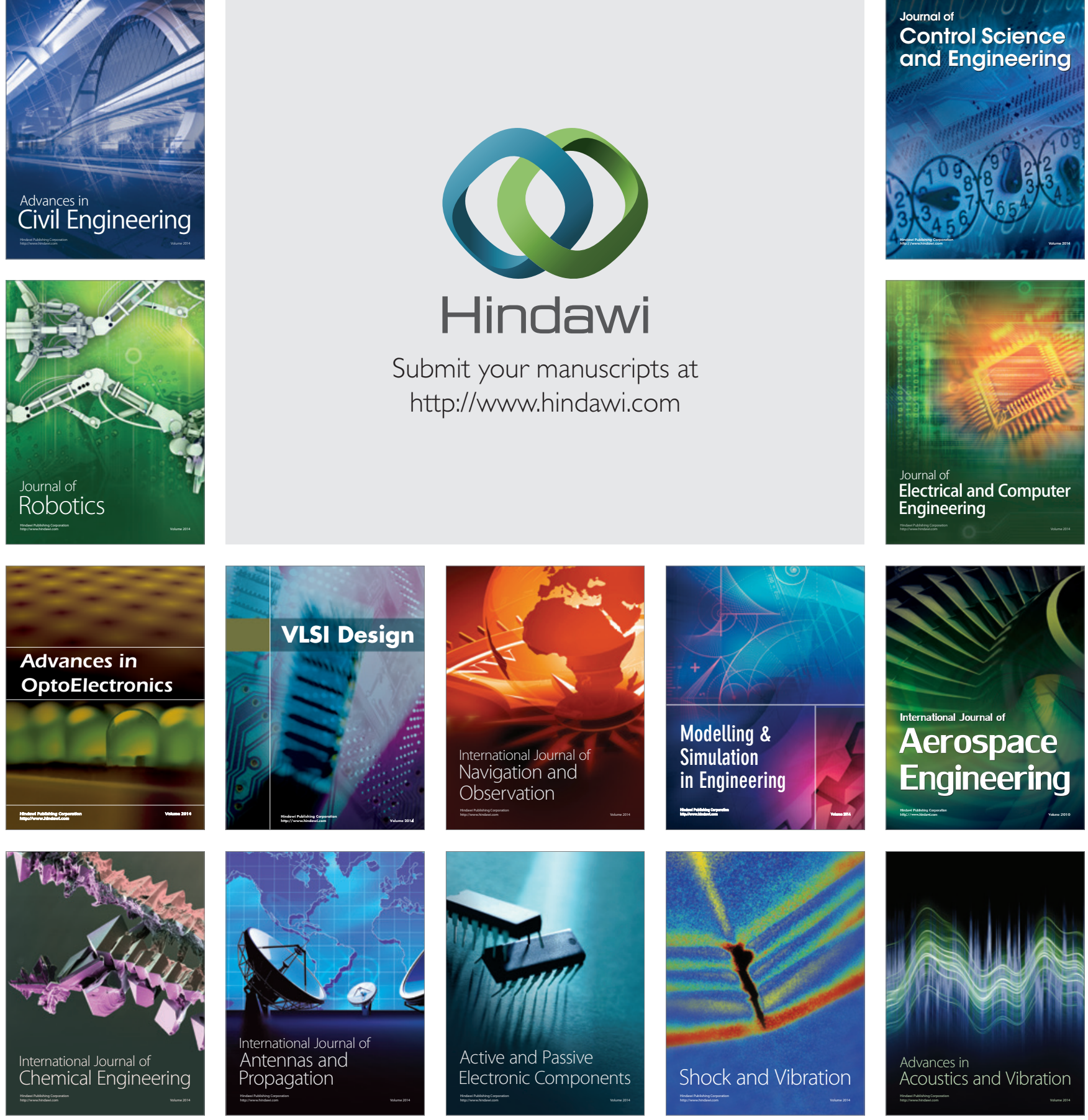